Prepared for the U.S. Department of Energy

under Contract DE-AC05-76RL01830

\title{
User's Guide to Pre-Processing Data in Universal Translator 2 for the Energy Charting and Metrics Tool (ECAM)
}

D Taasevigen

November 2011

Pacific Northwest

NATIONAL LABORATORY

Proudly Operated by Battelle Since 1965 


\title{
DISCLAIMER
}

This report was prepared as an account of work sponsored by an agency of the United States Government. Neither the United States Government nor any agency thereof, nor Battelle Memorial Institute, nor any of their employees, makes any warranty, express or implied, or assumes any legal liability or responsibility for the accuracy, completeness, or usefulness of any information, apparatus, product, or process disclosed, or represents that its use would not infringe privately owned rights. Reference herein to any specific commercial product, process, or service by trade name, trademark, manufacturer, or otherwise does not necessarily constitute or imply its endorsement, recommendation, or favoring by the United States Government or any agency thereof, or Battelle Memorial Institute. The views and opinions of authors expressed herein do not necessarily state or reflect those of the United States Government or any agency thereof.

\author{
PACIFIC NORTHWEST NATIONAL LABORATORY \\ operated by \\ BATTELLE \\ for the \\ UNITED STATES DEPARTMENT OF ENERGY \\ under Contract DE-AC05-76RL01830
}

Printed in the United States of America

\author{
Available to DOE and DOE contractors from the \\ Office of Scientific and Technical Information, \\ P.O. Box 62, Oak Ridge, TN 37831-0062; \\ ph: (865) 576-8401 \\ fax: $(865)$ 576-5728 \\ email: reports@adonis.osti.gov
}

\begin{abstract}
Available to the public from the National Technical Information Service, U.S. Department of Commerce, 5285 Port Royal Rd., Springfield, VA 22161 ph: (800) 553-6847 fax: (703) 605-6900

email: orders@ntis.fedworld.gov

online ordering: http://www.ntis.gov/ordering.htm
\end{abstract}

This document was printed on recycled paper.

$(9 / 2003)$ 


\section{User's Guide to Pre-Processing Data in Universal Translator 2 for the Energy Charting and Metrics Tool (ECAM)}

D Taasevigen

November 2011

Prepared for

U.S. Department of Energy

Under Contract DE-AC05-76RL01830

Pacific Northwest National Laboratory

Richland, Washington 99352 



\section{Executive Summary}

This user guide was generated to help pre-process data with the intention of utilizing the Energy Charting and Metrics (ECAM) tool to improve building operational efficiency. There are numerous occasions when the metered data that is received from the building automation system (BAS) isn't in the right format acceptable for ECAM. This includes, but isn't limited to, cases such as inconsistent time-stamps for the trends (e.g., each trend has its own time-stamp), data with holes (e.g., some time-stamps have data and others are missing data), each point in the BAS is trended and exported into an individual .csv or .txt file, the time-stamp is unrecognizable by ECAM, etc. After reading through this user guide, the user should be able to pre-process all data files and be ready to use this data in ECAM to improve their building operational efficiency. 


\section{CONTENTS}

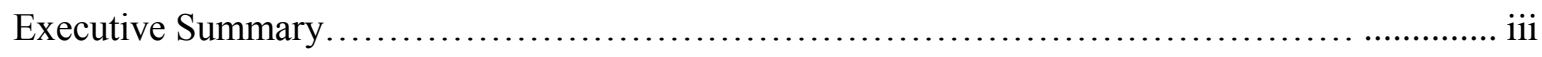

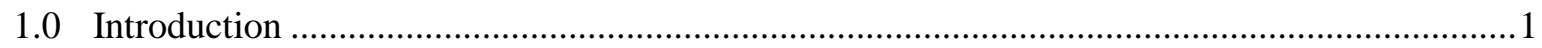

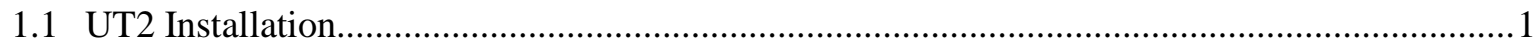

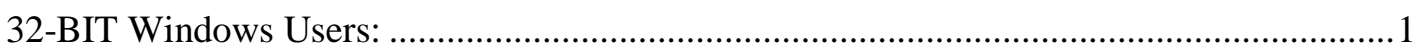

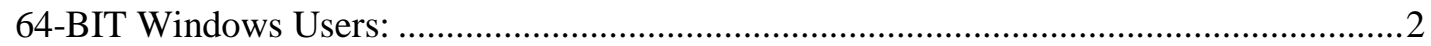

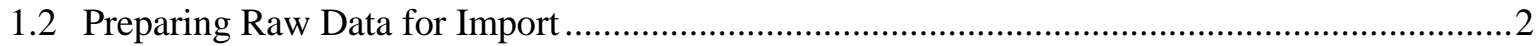

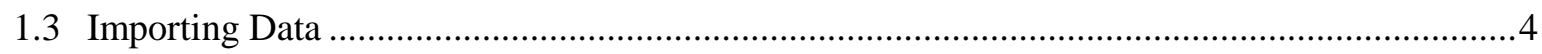

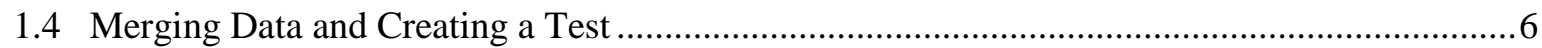

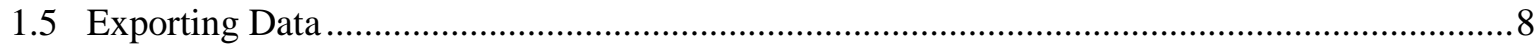




\section{FIGURES}

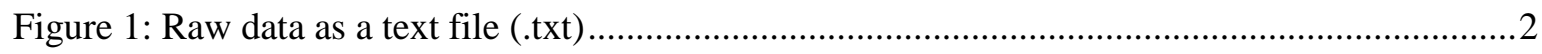

Figure 2: File extension changed to .csv and then opened in Excel for editing ................................ 3

Figure 3: Formatting the date/time stamp in excel.....................................................................

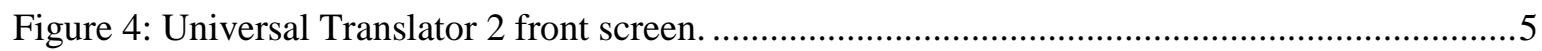

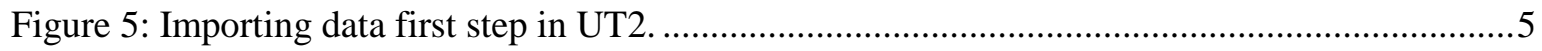

Figure 6: Inputting the channel descriptions and date/time format in UT2 .................................6

Figure 7: Channel properties window opened in UT2 ........................................................ 7

Figure 8: Creating a test and adding project channels to the test in U2 ....................................... 8

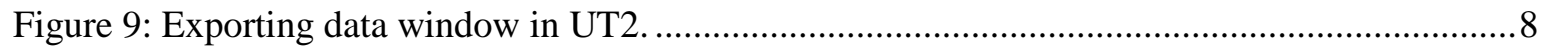





\subsection{Introduction}

The Energy Charting and Metrics (ECAM) tool is intended to facilitate the examination of energy information from buildings, reducing the time spent analyzing trend and utility meter data. In addition to being easy-to-use, this tool is also flexible. Key features of ECAM include the following:

- Data processing to attach schedule and day-type information to time-series data;

- Filtering by day-type, occupancy schedule, binned weather data, month/year, pre/post, etc;

- Normalization of data based on user-entered information;

- Creation of standard charts for the points selected by the user; and

- Calculation of normalized metrics for the points selected by the user.

The user's original data is not modified in the process of using ECAM, but is copied into a new workbook automatically. The tool makes extensive use of Excel ${ }^{\circledR}$ PivotTables to facilitate summarization and filtering of the data. It goes beyond normal PivotTables and PivotCharts, however, by automating the creation of scatter charts based on PivotTable data.

This document describes the use of the Universal Translator (UT2) to modify data that cannot be processed in ECAM directly (e.g., non-uniform time-stamp, missing data, multiple .csv files for end-use data).

\subsection{UT2 Installation}

The Universal Translator is a program that assists in processing and merging data that has non-uniform time intervals or is stored in multiple files. The Universal Translator can offer meaningful calculations despite inconsistent data. To install the application, go to www.utonline.org and create a free account. Follow the instructions to enter your information and setup a password. Once created, log into your account and click on the downloads tab and download UT2 Version 2.5.115. The website also offers a printable tutorial from the same page, which should be downloaded and read before installing.

\section{2-BIT Windows Users:}

To determine your computer's operating system details, go to start>control panel $>$ system. If the system is a 32-bit operating system, click on Version 2.5.115 and scroll down to the bottom of the next page until you see Attachment ut_setup_2_5_115.exe. Click the attachment and select run. Before UT2 can be installed, SQL Server Express must be installed on your computer. The installer will automatically guide you through this process. If reboot is required, do so when prompted, and the computer will finish the UT2 installation on re-boot. 


\section{4-BIT Windows Users:}

Some 64 BIT Windows users have had problems installing UT2 and have reported a runtime error. To avoid this error, a manual install of SQL Server is required. After clicking on Version 2.5.115, scroll down to the bottom of the page and instead of choosing the attachment, click on the READ THIS for 64 BIT Windows Users. Open the PDF attachment from the next page and read the instructions. The document will tell you to download "SQLEXPR32.EXE" (36.5 MB) and save it to your machine. Don't download this version, download "SQLEXPR.EXE" (55.4 MB). After you manually install SQL Server and follow all directions from the PDF attachment, run the UT 2.5.115 installer from www.utonline.org. This time the SQL install step will be skipped and UT2 will be installed properly. If you get a run-time error when opening UT2, try running it as an administrator by right clicking on the Universal Translator 2 and selecting "Run as Administrator." After UT2 has been installed, you must find where it is located. It will be put in the PEC folder under PEC/UniversalTranslator/utprogramfiles/utGUI.exe.

\subsection{Preparing Raw Data for Import}

Before importing data into UT2, it must be formatted into a .csv file. If data is downloaded manually into .txt files (Figure 1), save them as .csv files and open them in Excel to edit them (Figure 2). Depending on the time-stamp for the data, it may need to be edited for UT2 to recognize it. The "mid" function can be used in Excel to pull specific characters from any cell in Excel. This is useful in breaking up the time-stamp into multiple columns. The first column will have just the date, and the next column will have just the time. When importing the data into UT2, it will ask how many date/time columns. If you have more than one, it will merge them once imported into a recognizable date/time format for ECAM. Once the cells are formatted to the values of interest, save the file as a .csv file and exit. Repeat this for all files of interest.

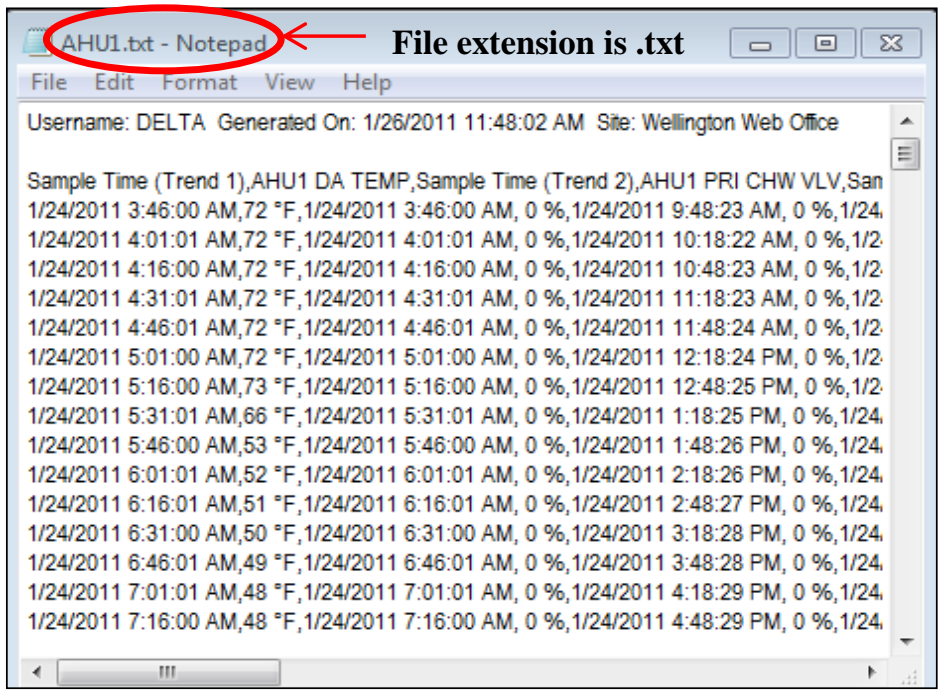

Figure 1: Raw data as a text file (.txt) 


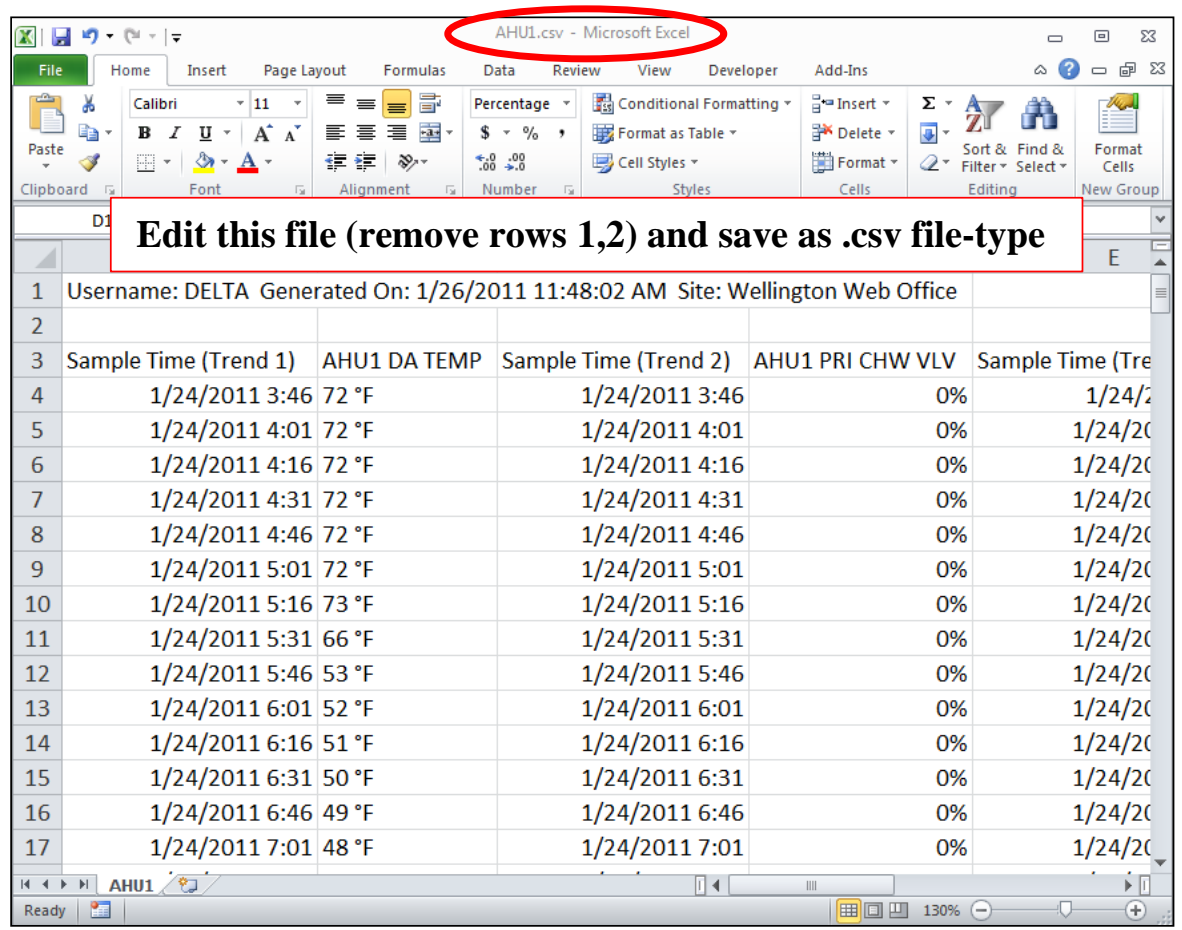

Figure 2: File extension changed to .csv and then opened in Excel for editing

The time-stamp in Figure 2 is a recognizable format for UT2, but UT2 will not process this file in its current form because each column of data has its own time-stamp. For cases such as these, save each trend (e.g., Sample Time (Trend 1), AHU1 DA TEMP in one file, Sample Time (Trend 2), AHU1 PRI CHW VLV in another file, etc.) in an individual .csv Excel file and then import into UT2. Importing data will be discussed in section 1.3 below.

The following steps apply to Figure 3 below, when the BAS system outputs a time-stamp that is unrecognizable by UT2.

- Figure 3 shows a .csv file with an invalid time-stamp. Using the command $(\operatorname{mid}(\mathrm{A} 1,1,10))$ will take the date/time-stamp and return the first 10 characters, or just the date.

- The same argument can be used for the time stamp by inputting mid(A1,12,5). This argument starts at character 12 and returns the next 5 characters.

- Be sure to name the column (Date, Time, etc.) so it is recognizable once imported into UT2. 


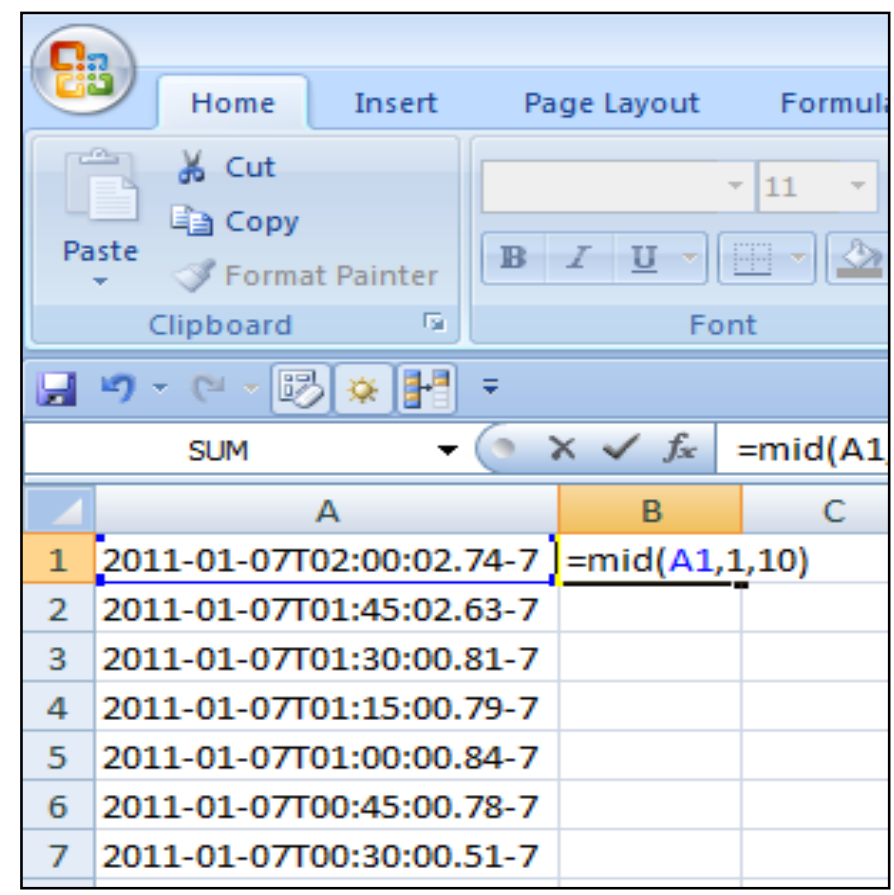

Figure 3: Formatting the date/time-stamp in Excel.

\subsection{Importing Data}

Open UT2, and you will be prompted to create a new project or open the UT tutorial. The tutorial will work for most functions of UT2, but you can create a new project also. Figure 4 below shows the home screen of UT2 after selecting a project. The main components of UT2 are the "Project Channels/Categories" pane, the "Datalogger Files" pane, the "Tests" pane, and "Filters." For this exercise, all parts of UT2 will be used except the "Filters."

\section{Step 1: Go to Project/Import Data from the UT2 Menu}

After clicking "Import Data," choose one of the .csv files that you have saved on your local drive. Once chosen, a new window will come up, giving options for data logic type, data format type, and which row to start importing data (Figure 5). For .csv files, the data format type will be delimited, the data logic type will be time series, and the row will most likely be the first row, but double check this from the .csv file. Once sure of all three options, click next. 


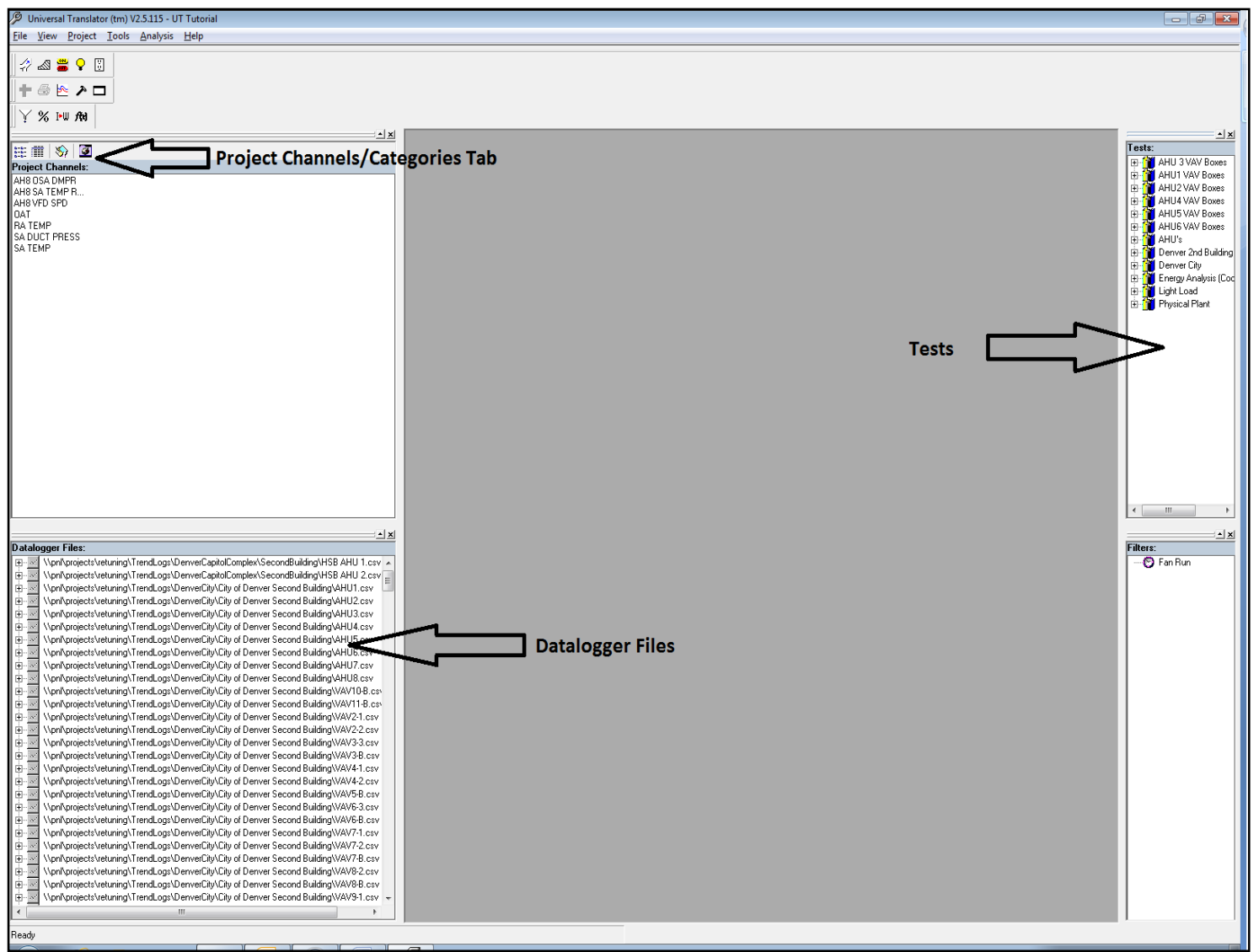

Figure 4: Universal Translator 2 front screen.

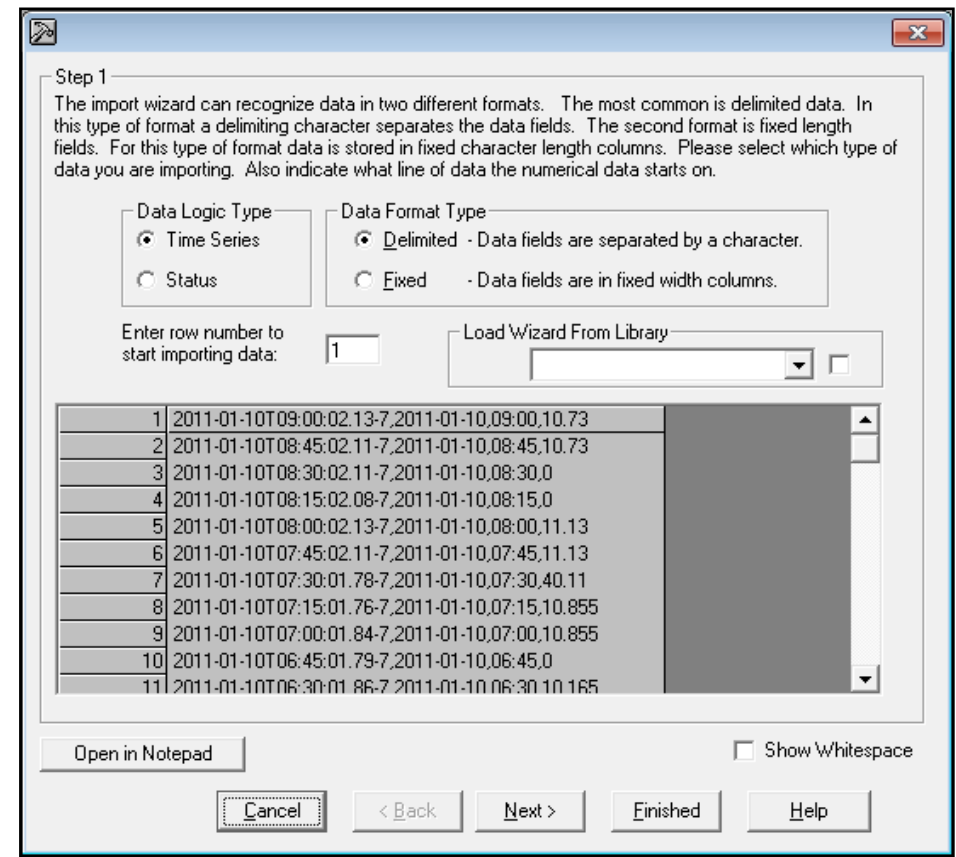

Figure 5: Importing data first step in UT2. 


\section{Step 2: Input Channel Descriptions and Date/Time Format}

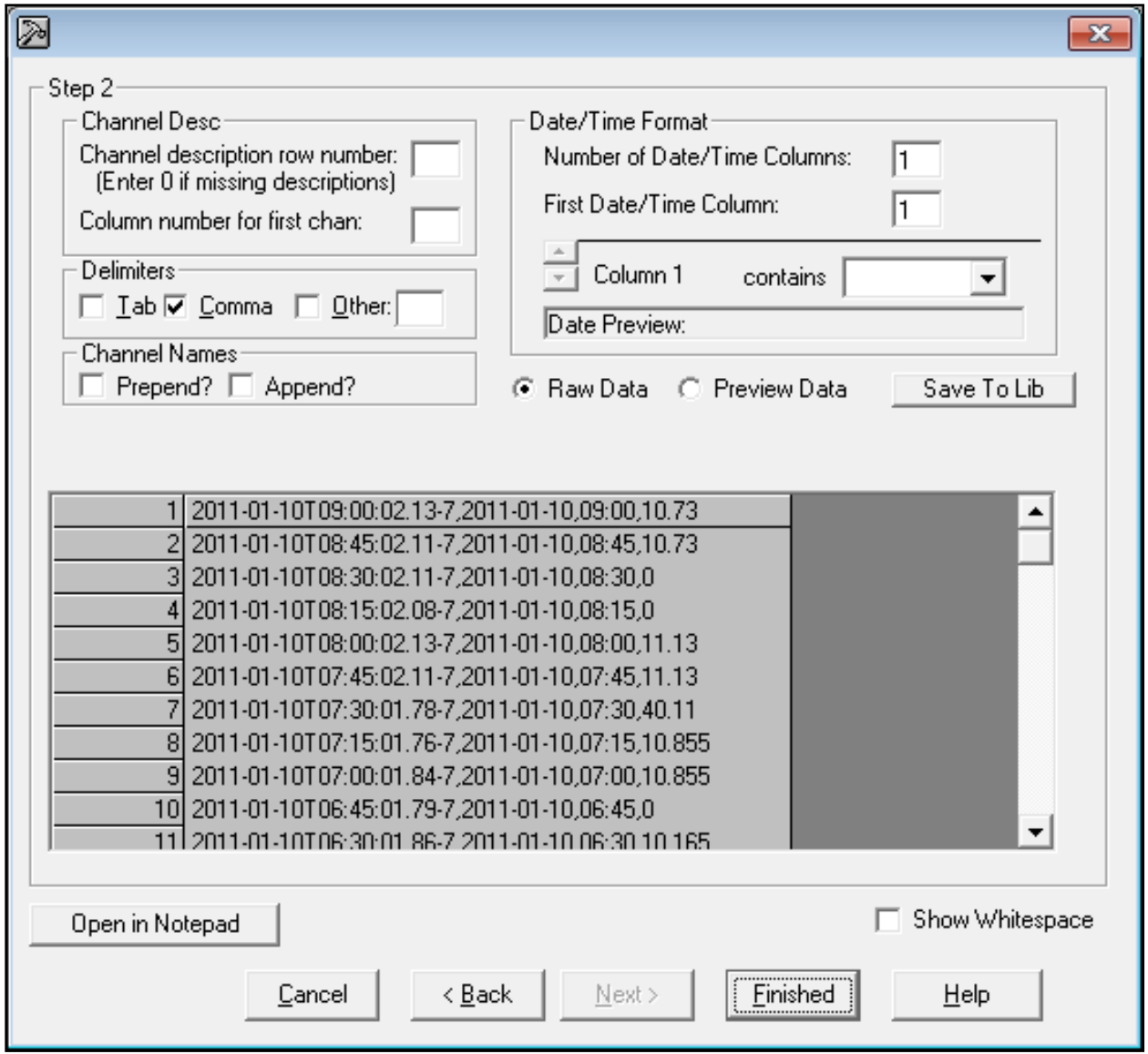

Figure 6: Inputting the channel descriptions and date/time format in UT2.

After clicking next, a new window will pop up to input channel descriptions and the date/time format (Figure 6). Check the .csv file and count how many columns are occupied by the date and time-stamp, then specify that in the "Date/Time Format" section in Figure 6 above. If the channels in the .csv file are named, you want to specify that in the "Channel Description" part of this window by selecting the row number that has the descriptions and the column that you want to start importing names (exclude column for date/time). If you are unsure of the selection, click the preview data button to see how UT2 recognizes the data. Once this preview is correct, click "Finished."

The data will be imported in the "Datalogger Files" pane of the UT2 main screen and the file name will appear. Repeat these first 2 steps until all .csv files have been imported into UT2.

\subsection{Merging Data and Creating a Test}

Before merging the data, a category must be created to group all .csv files together. To create a category, click the "Show Categories" tab above the "Project Channels" window. Right click in the window, and select "Add Category", and a "New Category" will appear 
in the window. To name the category, right click on it and select "Edit Category Name." Now toggle back to the "Project Channels" window. To add the data, simply drag and drop a file name from the "Datalogger Files" into the "Project Channels" window. If the channels have already been named, the names will show in the window now. If they haven't been named, double click on each one and a window will come up with options for changing the name, adding units, and adding attributes (Figure 7). Naming the channels before loading into UT2 is advantageous because UT2 simply gives default names to un-named data files (e.g. Channel001, Channel002). This will make using ECAM more difficult, so it is recommended that you properly name the channels before continuing.

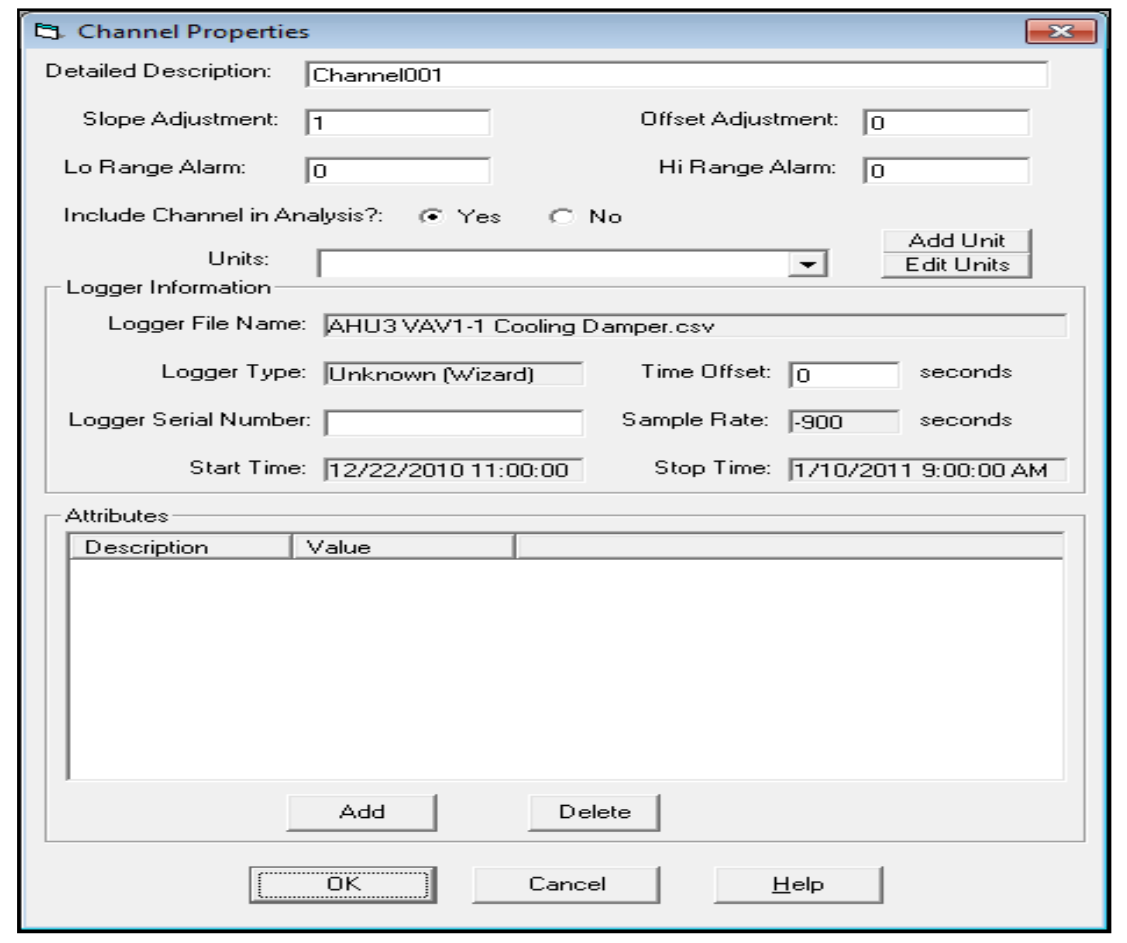

Figure 7: Channel properties window opened in UT2.

Now toggle back to the categories window, right click on the named category, and select "Add all Project Channels to this Category." A drop down list will show up with all of the channels listed. Once the category has been created and all channels are added, a test must be created.

The Tests window should show up on the top right of the UT2 main window as in Figure 3. If it doesn't show there, go to View $>$ Tests to open it. Right click in the window and select "Add Test." 
Adding a test will bring up a screen similar to that shown in Figure 8. Name the test under the "Test Description", and change the correlating interval to the time interval you want to process the data. For 15-minute intervals, the correlating interval would be 900 seconds. On the left hand side will be the "Available Channels" to add. Add as many channels as you want and then pick a start and end time to process the data. If you want UT2 to match the time-stamp for you, click on the "Max Concurrent" button. When done, click ok. The created test will now show up in the "Tests" window.

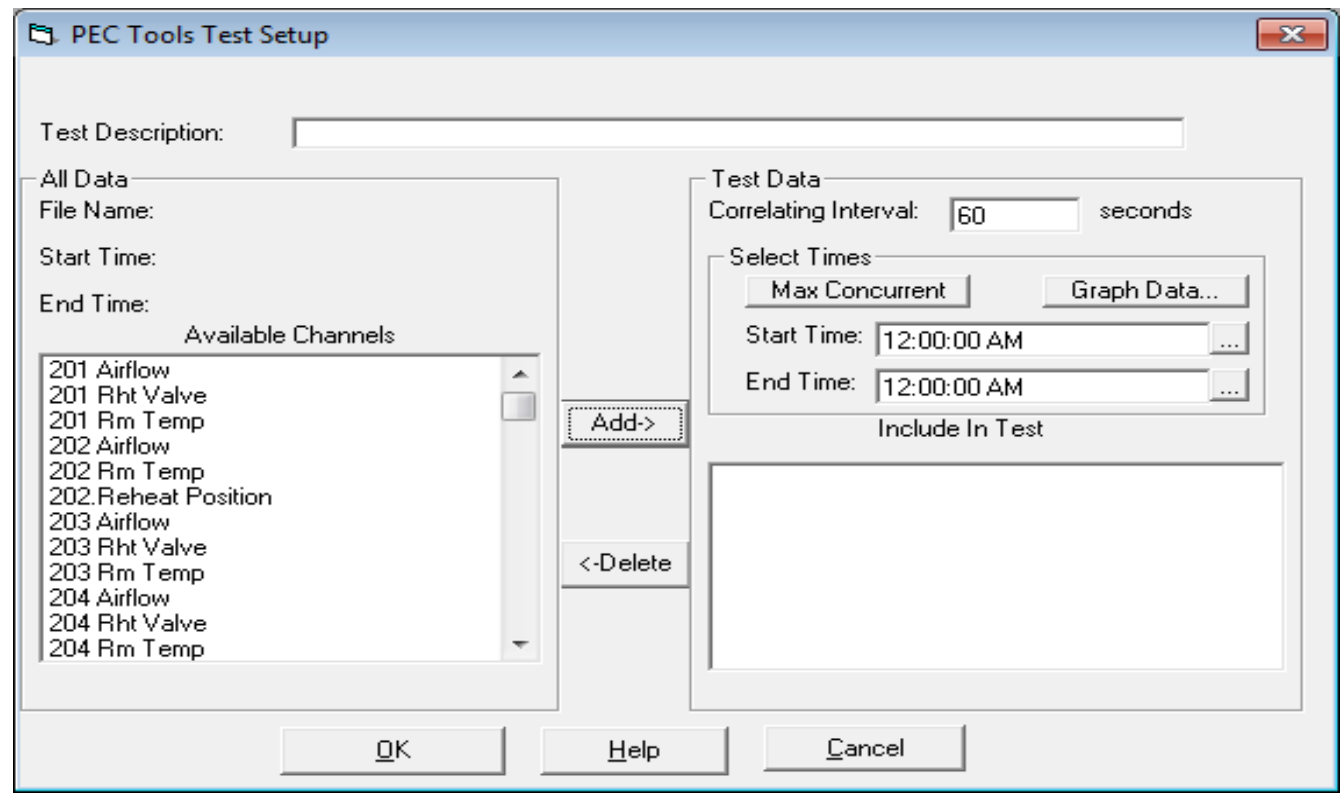

Figure 8: Creating a test and adding project channels to the test in $\mathrm{U} 2$.

\subsection{Exporting Data}

To export the data, go to File>Export Data, and the window in Figure 9 will appear.

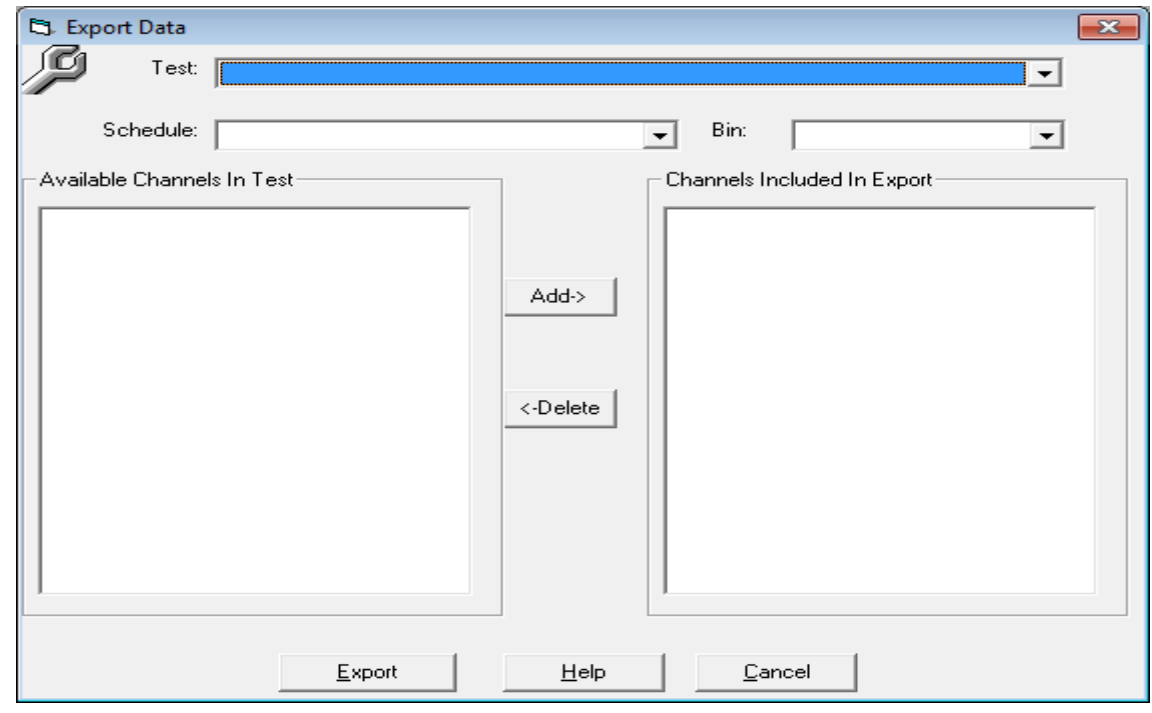

Figure 9: Exporting data window in UT2. 
From the drop down menu, choose the appropriate test according to the name you gave it in the previous step. All of the available channels within that test will show on the left hand side of Figure 9. Select them all and click the "Add" button to add them in the "Channels Included in Export" window. Now let UT2 process the data. If there are any duplicates in time stamps or data is missing from the .csv files, UT2 will prompt the user of these instances and give options for skipping those data points. Once the data is done processing, click "Export." The file extension from UT2 is .UTF, and this file type is compatible with Microsoft Excel. Open the file in Excel; delete rows 1,2, and 4; and then re-name the first column as "Date" or "Time." Once finished, save this file as a .csv file and you are now ready to use ECAM on this data set.

Note: the default value for missing or "No Data" fields in UT2 is 0. Also, if there is data that has command values such as "Yes" or "No", UT2 will convert "Yes" to 1 and "No" to 0 when processing the data. 


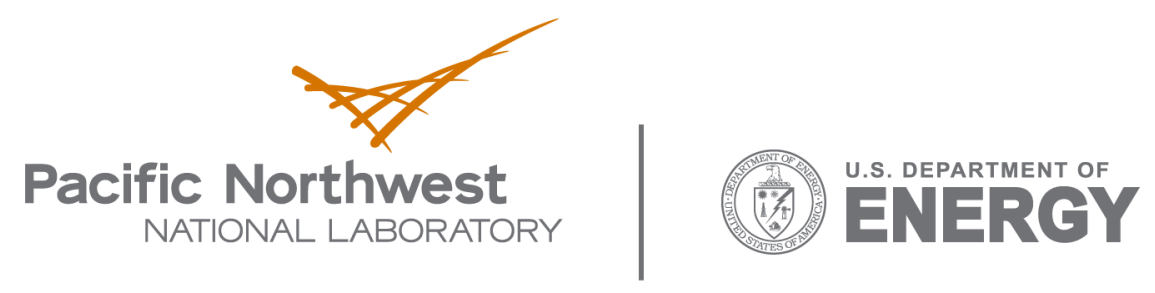

902 Battelle Boulevard

P.O. Box 999

Richland, WA 99352

1-888-375-PNNL (7665)

www.pnl.gov 